climate change. But how much cheaper? There's the rub.

A study in Nature this week offers the latest and most comprehensive attempt to address this question (see page 549). Marshall Burke and his colleagues modelled the impact of historical temperature changes on the gross domestic product (GDP) of 165 countries between 1960 and 2010. They then ran the model to the end of this century to plot what would happen to GDP according to how much average temperature rise was expected. The results show that greater action to curb temperature will bring greater economic benefits - which are, in reality, avoided damages, measured as the impact on GDP.

Specifically, there is a $75 \%$ chance that keeping global warming to a $1.5^{\circ} \mathrm{C}$ rise - an aspiration of the Paris climate treaty - will leave the world better off than letting it run to a $2^{\circ} \mathrm{C}$ rise. The probable savings: a cumulative US $\$ 20$-trillion increase in world GDP by the end of the century. (Global GDP in 2016 was about $\$ 76$ trillion.)

It's fair to say that not all of the world's economists and climatepolicy wonks will be content to take the conclusions of the study at face value. Details matter, not least - as with all models - the kinds of assumptions made and data used. The Stern Review, for example, was quickly queried by economists who criticized the way in which it borrowed from the insurance industry and placed great importance on the needs of future generations, who are usually discounted in models of economic impact because it is assumed that they will be considerably richer and so better able to deal with problems than are today's generation.

In that spirit of debate, this week we also publish two - conflicting - opinions on this study in a News \& Views Forum (see page 498). It provides a glimpse of the debate already raging in the economics community. One point of contention is how fair it is to simply extrapolate from past trends into the future. As finance experts are keen to point out, past performance is not always a reliable guide to future yields, and in this case it could be that the people of the future will find ways to adapt to a changing climate that are not accounted for in the model. Such adaptation - the development and widespread introduction of drought-resistant crops, for instance - would offer a significant saving, because food prices would not increase so dramatically if harvests are protected.

"Our burning
of fossil fuel
is writing
cheques that our
economy can't
afford to cash."

Another feature of the new model is that it assumes that climate change, and the extreme weather it is expected to bring, will have a compound impact on the rise of a nation's GDP. Thus, a devastating storm or washedout summer would affect not just that year's economic performance, but also its performance in subsequent years. Previous studies have taken a more optimistic view that any damage could quickly be compensated for.

There is a more fundamental issue, too. Just how reliable is GDP as a metric? Famously, it assumes that the market price of goods and services fully reflects the costs of their production and use. And the economics of climate change don't always do that: the price of fossil fuels, for one, doesn't take account of the costs associated with future warming.

Like all models, these economic projections will be argued over, worked on and ultimately improved. Scientists can gather the data to help that process, for example by expanding studies of the regional effects of climate change to poorer nations that are already bearing the brunt of the physical and economic impacts. Meanwhile, the arguments for acting on greenhouse-gas emissions, already many and varied, just got a little stronger. Our burning of fossil fuel is writing cheques that our economy can't afford to cash.

\section{Road to nowhere}

\section{Electric cars are gaining ground fast but face fossil-fuel favouritism in the showroom.}

\section{$\mathrm{W}$} ho killed the electric car? According to the 2006 documentary of that name it was the automobile companies, and especially General Motors (GM), which produced, and then recalled and crushed, thousands of its pioneering EV1 model in the late 1990s. Arguments still rage about the company's true motives (GM insists it was down to high costs), but two decades on from the EV1 with its niche appeal, it's clear that reports of the death of electric vehicles have been greatly exaggerated. Sales in some places are booming. Figures from the Centre of Automotive Management in Gladbach, Germany, show that nearly half of the new vehicles registered in Norway during the first three months of this year were electric. During the same period, China sold more than 142,000 electric vehicles - still just $2 \%$ of the total numbers sold, but a large increase on last year.

What drives these sales? According to a study published this week in Nature Energy (G. Zarazua de Rubens, L. Noel \& B. K. Sovacool Nature Energy https://doi.org/10.1038/s41560-018-0152-x; 2018), it's not the sales staff who work at car dealerships - at least not in most nations in Scandinavia. "Do not buy this, it will ruin you," one prospective buyer was told when they asked about an electric car on sale. "Another would-be customer was gently steered away from an electric model because, the sales person wrongly insisted, it would take two days to drive 350 kilometres - roughly the distance between New York City and Washington DC.

We know this because, in these cases, the customers had no intention of buying a car - electric or otherwise. They were undercover university researchers, indulging in a little 'mystery' shopping to test industry attitudes and the barriers that remain to the widespread adoption of new technologies. In this case, the attitude of the sales staff - largely driven by them not knowing as much about the electric models - was hugely influential. The study analysis suggests that it is the most important predictor of the likelihood that a customer will leave having bought an electric car - which the researchers calculated was a dismal $0 \%$ in many of the cities they visited.

In all, the researchers underwent 126 shopping experiences in 82 car dealerships across Denmark, Finland, Iceland, Norway and Sweden. (The ethics of mystery-shopping exercises have been questioned - they waste the time and money of the targets - so the researchers did not spend more than about ten minutes talking to the sales staff in each case.) They conclude that dealers were dismissive of electric vehicles and misinformed shoppers about vehicle specifications. In many cases, it took persistent questions from the mystery shoppers to get the electriccar dealers just to admit that yes, they did actually sell electric cars.

Why would car sales staff make it so difficult for customers to buy a car? Because they want them to buy a different kind of car. As the researchers point out, dealers "strongly oriented customers towards petrol and diesel vehicle options" on sale alongside the electric versions. And that behaviour is typical. The researchers argue that the attitude "mirrors industry and government favouritism towards conventional cars".

Why does this matter? Electric cars are an important strategy for sustainable transport and have reached the point where sales to early adopters must start to give way to sales to a larger "early majority" (J. Lynes Nature Energy https://doi.org/10.1038/s41560-018-0173-5; 2018). There is a well-known and much-feared chasm between the two stages, and one that policymakers are trying to bridge with incentives such as subsidies, investment in infrastructure and privileged access to road space (such as allowing electric cars into lanes banned to other cars carrying no passengers). The mystery-shopping study highlights a new and important part of the bridge. Attitudes and incentives in dealerships must be changed - even simple steps such as better training and offering higher commission on successful sales of electric vehicles could help. 